\title{
Prevention of Oil Pollution of the Marine Environment by Ocean Vessels: Compliance and Enforcement of International Law.
}

\author{
A. Z. M. Arman Habib \\ LL.M. (International Law), ( ${ }^{\text {st }}$ Semester), Faculty of Legal Studies, South Asian University, New Delhi, India.
}

\begin{abstract}
In an increasingly environmentally conscious world, ship-source marine pollution has, for a long time, been singled out for special attention. While large oil pollution incidents have reduced both in number and in size over recent decades, the potential threat of environmental damage and economic loss associated with the carriage of oil remains disconcerting. In the last century the world experienced some major oil spills of the time with catastrophic effects to marine environment. Responding to such unfortunate events, among other things, enacted liability and compensation conventions to ensure timely and adequate compensation to victims of oil pollution. Even so, the application of such conventions raised some questions. This paper focuses on the international legal framework for prevention of vessel-source oil pollution. Regulatory international law regarding prevention of vessel-source Oil pollution is discussed within the framework. This paper examined the role of oil pollution liability conventions in the protection of marine environment through compensation and challenges facing the conventions in the process of application in relevant oil pollution incidents. The relevant issues have, therefore, been discussed and analyzed.
\end{abstract}

Key Words:Marine environment, Vessel source pollution, Oil pollution, Marine environment protection, International liability legislation.

\section{Introduction:}

"Shipping in the $21^{\text {st }}$ century underpins international commerce and the world economy as the most efficient, safe and environmentally friendly method of transporting goods around the globe. We live in a global society which is supported by a global economy and that economy simply could not function if it were not for ships and the shipping industry."

The above comments highlight the importance of the shipping on the international commerce especially considering that more than $90 \%$ of the world trade is carried by sea. ${ }^{2}$ The Ocean covers approximately $70 \%$ of the earth's total surface area. In the total water content of earth, $97 \%$ is present in the Oceans. ${ }^{3}$ It harbors rich source of biodiversity, which population may exceeds in trillions. ${ }^{4}$ Oceans are the main regulatory agent of earth's climate. About $60 \%$ of the world's population live within $60 \mathrm{~km}$ of coastline and use the coastline for their livelihood. ${ }^{5}$ Statistical sources states that over $90 \%$ of all trade between countries is carried by ships. ${ }^{6}$ Some 50,000 merchant ships sail the world's oceans, transporting everything from food and fuel to construction materials, chemicals, and household items. In 2003, around 6.1 billion tons of cargo was shipped by sea, covering a collective distance of over 6 million kilometers. ${ }^{7}$ Protection and preservation of marine environment has become one the most important ecological issues of modern time. ${ }^{8}$ The major pollutants like oil, sewage, garbage, toxic chemicals, pesticides, heavy metal, radioactive waste, thermal pollution, and eutrophication in coastal and marine environments, their characteristics and principal impacts are discussed in detail. ${ }^{9}$ After the Second World War not only the public interest in the environment increased in general. Concerns of coastal states about increasing ship-source marine pollution and oil spills started to grow as well. Some of the occurred incidents with tankers clearly demonstrated that oil spills in an environmentally or

\footnotetext{
${ }^{1}$ International Maritime Organization, International Shipping, Carrier of World Trade, (2006). From www.imo.org/includes/blast Data Only/data_id=12908. (Accessed on 1-Sep-14).

${ }^{2}$ Dr. N. V. Vinithkumar, Marine Pollution a Perspective, Monitoring and Control in India, 1stedn., (Marine Institute of India.2012). http://www.niot.res.in/m5/mbic/me/data/me.pdf

${ }^{3} I d$.

${ }^{4} I d$.

${ }^{5} I d$.

${ }^{6} \mathrm{Id}$.

7 http://wwf.panda.org/about our earth/blue planet/problems. (Accessed on 1-Sep-14).Mr. Ruben Maceda, LEGAL ANALYSIS OF INTERNATIONAL CONVENTIONS FOR THE PREVENTION OF VESSEL-SOURCE MARINE POLLUTION: A MALDIVIAN PERSPECTIVE, A Dissertation submitted in partial fulfillment of the requirements for the award of the Degree of Master of Laws (LL.M.) in International Maritime Law at the IMO International Maritime Law Institute, UNEP(DEPI)/MED WG.384/INF.7, 6 June 2013.

${ }^{8}$ Jin-Tan, Alan Khee, Vessel-Source Marine Pollution, (Cambridge University Press; Cambridge, 2006).

${ }^{9}$ Supra note 2 .
} 
economically sensitive area could cause irreparable damage. ${ }^{10}$ Oil pollution of the ocean comes from shipping activity and offshore oil production. Sea-bed activities on oil exploration and production constitute a relatively small part in the general amount of the pollution of marine environment with oil. The principal cause of marine pollution with oil is shipping. Traditionally shipping is considered to be "a polluting industry". The world's tanker fleet counts approximately 7000 vessels with cargo capacities between 76000 and 175000 tons. ${ }^{11}$ Usual shipping operations, especially transportation of oil by tankers and accidents, result in the dumping of around $600000-1750000$ tons of oil into the ocean per year. ${ }^{12}$

Of all the pollutants entering the sea, oil seems to attract the greatest attention. Similarly, oil tanker incidents are often perceived as the most important sources of marine pollution. Although it is the dramatic incidents that catch the headlines, oil wastes that enter the ocean come from many sources. Oil spills actually occur every day. ${ }^{13}$ The last oil pollution incident, which gained publicity and attention of the mass media, happened in October 2011 off the New Zealand's coast. ${ }^{14}$ The grounding off of the tanker "Rena" and the followed oil leaking caused the environmental disaster. This oil spill seriously damaged wildlife, including penguins, seals, dolphins, whales and rare sea birds ${ }^{15}$ Hence the law governing vessel-source pollution covers accidental oil spill to operational discharges and deliberate dumping of wastes. Furthermore, vessel-source marine pollution law today isbecoming more comprehensive and extends to more specific aspects such as ballast water as well as exhaust emissions from ships. ${ }^{16}$ It is therefore necessary to provide a clear understanding of the legal framework of vessel source pollution. ${ }^{17}$

The objectives of the research undertaken in this article are, to know the impact of the oil pollution of the marine environment by ocean vessels, to examine critically the present status of oil pollution of the marine environment by ocean vessels, to examine critically legal basis of prevention of oil pollution of marine environment by ocean vessels. The central goal of this research is to examine how the liability system for marine oil pollution damage is designed and has developed since its existence whether it functions effectively and whether the aim of the system being fully compensate oil pollution victims has been accomplished and if such an aim is receded in efficient way.

\section{Effects of Oil Pollution in the Marine Environment:}

The environmental impacts of spilled oil can be severe. The damage caused by a spill depends on location; volume and type of oil spilled, weather conditions, season, and many other factors. Large spills cause widespread immediate impacts, and potential long-term damage to parts of affected ecosystems. However, chronic discharges such as from street runoff and improper oil disposal are also damaging. Cumulative chronic discharges far exceed major spills in volume. Cleanup operations remove some, but not all, oil from the environment; the oil that remains naturally degrades over time. ${ }^{18}$ On top of that, there is the Deep water Horizon Oil Spill of 2010 which is so far considered the largest oil spill of all times. ${ }^{19}$ In the named oil spill incidents, the adverse effects of hydrocarbons has been demonstrated evidently; the damage to shoreline, marine ecosystem, fisheries and coastal amenities are remarkable. ${ }^{20}$ Such damage corresponds to financial, commercial, and other related losses. ${ }^{21}$ Preventive measures, clean-up operations and restoration, property damage have all proved to cost to a great extent both resources and time. Besides, the cost of damage done to the environment can neither be quantified nor fully recovered. ${ }^{22}$ Despite the fact that oil pollution at sea was first recognized as a problem during World War I, the first international convention on prevent oil pollution at sea was adopted after World War II. ${ }^{23}$

\section{Effects of Oil Pollution on Coastal Habitats:}

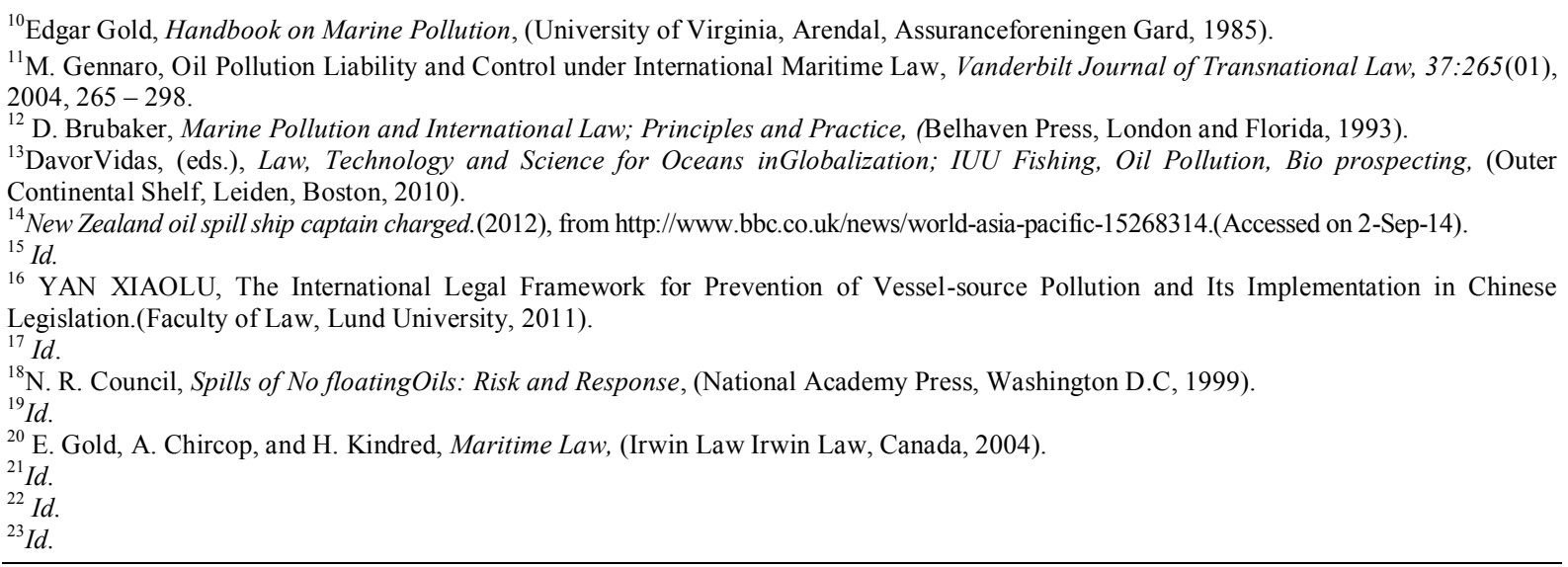


Coastal areas are particularly susceptible to oil pollution. When a large spill drifts ashore, some of the oil may become trapped and remain for years. This is in contrast to the open sea where currents and diffusion rapidly reduce the concentration of oil. While shoreline impacts are very situation-specific, immediate effects of heavy oiling may be evident by the death of plants and animals due to smothering and toxicity. In some situations, oil may persist for many years, causing less apparent but harmful chronic effects. ${ }^{24}$ In rocky shore areas, stranded oil may coat the rocks and gradually harden by weathering into a tough tarry "skin." This oil is gradually removed by wave erosion, but pools of oil that collect form a skin of weathered oil and may remain for a long time.On cobble and sandy beaches, oil can sink more deeply into the sediments and can remain longer than on bare rocks. Tidal pumping and sediment grain size effect the rate of penetration. In muddy sediments, penetration is minimal. Tidal flats are broad low-tide zones, usually containing rich plant, animal and bird communities. Oil may seep into the muddy bottoms and have long term impacts. Salt Marshes have a wide variety of plant and animal species. Oiling of such systems may reduce the population and growth rate of the marsh plants and dependent species. ${ }^{25}$

\section{Effect of Oil Pollution on Organisms:}

Existence of contamination by these chemicals in the environmental media leads to potential impact on almost all species including human. All the organisms, obtain their first dosage of these chemicals from their food and water, while the mammalian species derive these toxins from theirs mothers through milk. While the plants and lower trophic level organisms also accumulate these chemical in their bodies, the effect of these chemicals on these organisms in not openly seen. ${ }^{26}$ Organ chlorines have been found to cause microsomal enzyme induction, accelerating body steroids such as estrogens and also to have an effect on the normal reproductive activities of many experimental animals. It is generally known that $5 \%$ eggshell thinning occurs at a concentration $5 \mathrm{mg} / \mathrm{g}$ of DDE $\mathrm{DD}^{27}$ in the bird egg. It is also found that concentrations of $20-1000 \mathrm{mg} / \mathrm{g}$ of DDE in the liver of birds are considered to pose a threat to individual bird reproduction and therefore on the population as a whole. ${ }^{28}$

\section{Effect of Oil Pollution on Ecological Disruption:}

Perhaps the most important effect of pollutants in the marine environment is ecological disruption, i. e. the imbalance created between organisms and their environment, and between communities of organisms of different species. Large changes in populations of commercially important fishes. Inland bodies of water, such as Lake Erie, where fine fishes have been replaced by coarse fishes, are only too well known. It occurs by complex processes in the ecosystem which are poorly understood. Ecological effects of pollution are of the most vital concern. ${ }^{29}$ This is often an insidious, long-term effect which can lead to the net result of pollution in from the point of view of protection of living resources in the marine environment, the Substances with unfavorable ecological effects, but without proven human health hazard, meet with considerable resistance when attempts are made to curtail or ban their use. ${ }^{30}$

\section{International Instruments on Marine Environment Pollution:}

Various international instruments have been created to regulate vessel source pollution. Those conventions constitute an international legal framework for vessel-source pollution. The framework comprises a series of international conventions from public international law (including pure public international law and regulatory international law) to international private law, touching every aspect of the vessel-source pollution from prevention, mitigation to remedy. Here included some list of international conventions related to shipsource marine oil pollution those are:

\subsection{International Convention for the Prevention of Pollution from Ships (MARPOL): ${ }^{31}$}

Adoption: 1973 (Convention), 1978 (1978 Protocol), 1997 (Protocol - Annex VI); Entry into force: 2 October 1983 (Annexes I and II)

\footnotetext{
${ }^{24}$ D. Brubaker, Environmental Protection of Arctic Waters Specific Focus the Northern Sea Route,(Stockholm, 2002).

${ }^{25}$ Spills of No floating Oils: Risk and Response, National Research Council, (National Academy Press. Washington D.C, 1999).

${ }^{26}$ Al, R. C., The Law of the Sea, $2^{\text {nd }}$ edn, (Manchester, UK: Manchester University Press, 1988).

${ }^{27}$ DichloroDiphenylidichloro Ethylene (DDE), which is formed by the loss of one hydrogen chloride molecule from DDT. It is a common breakdown product of DDT and also builds up in fat deposits in animals.

${ }^{28}$ R. A Duce, P. L. Parker \& C. S. Giam., Pollutant transfer to the marine environment, Deliberations and recommendations of the NSF/ IDOE pollutant transfer workshop held in Port,(Texas, USA: Kingston, Rhode Island, 1974).

${ }^{29}$ CALIFORNIA ENERGY COMMISSION. 2001. Oil pollution on birds in the San Francisco Bay region. California Fish and Game 24: 239-244.

${ }^{30}$ A. B. Patricia Birnie, International Law and the Environment.(OUP 2009).

${ }^{31}$ Supra note 8 , at 248 .
} 
The International Convention for the Prevention of Pollution from Ships (MARPOL) is the main international convention covering prevention of pollution of the marine environment by ships from operational or accidental causes. The MARPOL Convention was adopted on 2 November 1973 at IMO. The Protocol of 1978 was adopted in response to a spate of tanker accidents in 1976-1977. As the 1973 MARPOL Convention had not yet entered into force, the 1978 MARPOL Protocol absorbed the parent Convention. The combined instrument entered into force on 2 October 1983. In 1997, a Protocol was adopted to amend the Convention and a new Annex VI, was added which entered into force on 19 May 2005. MARPOL has been updated by amendments through the years. The Convention includes regulations aimed at preventing and minimizing pollution from ships both accidental pollution and that from routine operations and currently includes six technical Annexes. Special Areas with strict controls on operational discharges are included in most Annexes.

Annex I, Regulations for the Prevention of Pollution by Oil (entered into force 2 October 1983): ${ }^{32}$

Covers prevention of pollution by oil from operational measures as well as from accidental discharges; the 1992 amendments to Annex I, made it mandatory for new oil tankers to have double hulls and brought in a phase in schedule for existing tankers to fit double hulls, which was subsequently revised in 2001 and 2003.

\section{Annex II, Regulations for the Control of Pollution by Noxious Liquid Substances in Bulk (entered into force 2 October 1983): $:^{33}$}

Details the discharge criteria and measures for the control of pollution by noxious liquid substances carried in bulk; some 250 substances were evaluated and included in the list appended to the Convention; the discharge of their residues is allowed only to reception facilities until certain concentrations and conditions (which vary with the category of substances) are complied with.In any case, no discharge of residues containing noxious substances is permitted within 12 miles of the nearest land.

\subsection{International Convention on Civil Liability for Oil Pollution Damage (CLC), 1969: ${ }^{34}$}

(Adoption: 29 November 1969; Entry into force: 19 June 1975;Being replaced by 1992 Protocol: Adoption: 27 November 1992; Entry into force: 30 May 1996)

TheCivil Liability Convention, 1969, hereafter CLC, was adopted to ensure that adequate compensation is available to persons who suffer oil pollution damage resulting from maritime casualties involving oil-carrying ships. The Convention places the liability for such damage on the owner of the ship from which the polluting oil escaped or was discharged. The Convention requires ships covered by it to maintain insurance or other financial security in sums equivalent to the owner's total liability for one incident.The 1969 Convention applies to all seagoing vessels actually carrying oil in bulk as cargo (spills from tankers in ballast or bunker spills from ships other than other than tankers are not covered by the 1969Convention). The 1992 Protocol extends cover to spills from sea-going vessels constructed or adapted to carry oil in bulk as cargo so that it applies apply to both laden and unlade tankers, including spills of bunker oil from such ships.

The 1969 Convention covers pollution damage resulting from spills of persistent oils suffered in the territory (including the territorial sea) of a State Party to the Convention. The 1992 Protocol widened the scope of the Convention to cover pollution damage caused in the exclusive economic zone (EEZ) or equivalent area of a State Party.The Protocol of 1984 set increased limits of liability but was superseded by the 1992 Protocol. In 2000further amendments raised the compensation limits of the 1992 Protocol (adoption of these amendments: 18 October 2000 Entry into force: 1 November 2003), are as follows:

$>$ For a ship not exceeding 5,000 gross tonnages, liability is limited to 4.51 million SDR. ${ }^{35}$

$>$ For a ship 5,000 to 140,000 gross tonnage: liability is limited to 4.51 million SDR plus 631 SDRfor each additional gross tons over 5,000.

D For a ship over 140,000 gross tonnage: liability is limited to 89.77 million SDR.

The 1992 Protocol covers pollution damage and environmental damage compensation is limited to costs incurred for reasonable measures to reinstate the contaminated environment. It also allows expenses incurred for preventive measures to be recovered even when no spill of oil occurs, provided there was grave and imminent threat of pollution damage (successful preventative measure were no actual spill occurs are not covered by CLC).As of May 1998, Parties to the 1992 Protocol ceased to be Parties to the 1969 CLC due to a

\footnotetext{
${ }^{32}$ Id. at 250 .

${ }^{33} \mathrm{Id}$. at 256 .

${ }^{34}$ International Maritime Organization (IMO), http: //www.imo.org/Pages/home.aspx.(Accessed on 1-Sep-14).

${ }^{35}$ The SDR is an international reserve asset, created by the IMF in 1969 to supplement its member countries' official reserves. Its value is based on a basket of four key international currencies, and SDRs can be exchanged for freely usable currencies.
} 
mechanism for compulsory denunciation of the "old" regime established in the 1992 Protocol. However, there are a number of States which are Party to the 1969 CLC and have not yet ratified the 1992 regime which is intended to eventually replace the 1969 CLC.

\subsection{International Convention on Oil Pollution Preparedness, Response and Co-operation (OPRC): ${ }^{36}$} Adoption: 30 November 1990; Entry into force: 13 May 1995.

In July 1989, a conference of leading industrial nations in Paris called upon $\mathrm{IMO}^{37}$ to develop further measures to prevent pollution from ships. This call was endorsed by the IMO Assembly in November of the same year and work began on a draft convention aimed at providing a global framework for international cooperation in combating major incidents or threats of marine pollution.Parties to the International Convention on Oil Pollution Preparedness, Response and Co-operation (OPRC) are required to establish measures for dealing with pollution incidents, either nationally or in co-operation with other countries. Ships are required to carry a shipboard oil pollution emergency plan. Operators of offshore units under the jurisdiction of Parties are also required to have oil pollution emergency plans or similar arrangements which must be coordinated with national systems for responding promptly and effectively to oil pollution incidents.Ships are required to report incidents of pollution to coastal authorities and the convention details the actions that are then to be taken. The Convention calls for the establishment of stockpiles of oil spill combating equipment, the holding of oil spill combating exercises and the development of detailed plans for dealing with pollution incidents. Parties to the convention are required to provide assistance to others in the event of a pollution emergency and provision is made for the reimbursement of any assistance provided.

\subsection{International Convention on the Establishment of an International Fund for Compensation for Oil Pollution Damage (FUND): ${ }^{38}$}

Adoption: 18 December 1971; Entry into force: 16 October 1978; superseded by 1992 Protocol: Adoption: 27 November 1992; Entry into force: 30 May 1996.

Although the 1969 Civil Liability Convention provided a useful mechanism for ensuring the payment of compensation for oil pollution damage, it did not deal satisfactorily with all the legal, financial and other questions raised during the Conference adopting the CLC Convention. The 1969 Brussels Conference considered a compromise proposal to establish an international fund, to be subscribed to by the cargo interests, which would be available for the dual purpose of, on the one hand, relieving the ship-owner of the burden by the requirements of the new convention and, on the other hand, providing additional compensation to the victims of pollution damage in cases where compensation under the 1969 Civil Liability Convention was either inadequate or unobtainable.The Conference recommended that IMO should prepare such a scheme and the International Convention on the Establishment of an International Fund for Compensation for Oil Pollution Damage was adopted at a Conference held in Brussels in 1971. It is supplementary to the Civil Liability Convention.

\subsubsection{The purposes of the Fund Convention are:}

$>$ To provide compensation for pollution damage to the extent that the protection afforded by the 1969 Civil Liability Convention is inadequate.

$>$ To give relief to ship-owners in respect of the additional financial burden imposed on them by the 1969 Civil Liability Convention, such relief being subject to conditions designed to ensure compliance with safety at sea and other conventions.

$>$ To give effect to the related purposes set out in the Convention.

Under the first of its purposes, the Fund is under an obligation to pay compensation to States and persons who suffer pollution damage, if such persons are unable to obtain compensation from the owner of the ship from which the oil escaped or if the compensation due from such owner is not sufficient to cover the damage suffered.The Fund's obligation to pay compensation is confined to pollution damage suffered in the territories including the territorial sea of Contracting States. The Fund is also obliged to pay compensation in respect of measures taken by a Contracting State outside its territory.

The Fund is not obliged to indemnify the owner if damage is caused by his willful misconduct or if the accident was caused, even partially, because the ship did not comply with certain international conventions.

\footnotetext{
${ }^{36}$ Supra note 23 .

37 'International Maritime Organization - IMO' a specialized agency of the United Nations that is responsible for measures to improve the safety and security of international shipping and to prevent marine pollution from ships.

${ }^{38}$ Supra note 23.
} 
The Convention contains provisions on the procedure for claims, rights and obligations, and jurisdiction. Contributions to the Fund should be made by all persons who receive oil by sea in Contracting States.

Protocols to the 1971 convention were adopted in 1976 and 1984, but were superseded by the 1992 Protocol. Under the 1992 Protocol (Adoption: 27 November 1992. Entry into force: 30 May 1996), the maximum amount of compensation payable from the Fund for a single incident, including the limit established under the 1992 CLC Protocol, was raised to 135 million SDR. However, if three States contributing to the Fund receive more than 600 million tons of oil per annum, the maximum amount is raised to 200 million SDR.

6.5 The 2003 Protocol (Supplementary Fund): ${ }^{39}$ (Adoption: 16 May 2003. Entry into force: 3 March 2005)

The 2003 Protocol establishing an International Oil Pollution Compensation Supplementary Fund to supplement the compensation available under the 1992 Civil Liability and Fund Conventions with an additional, third tier of compensation. The Protocol is optional and participation is open to all States Parties to the 1992 Fund Convention. The total amount of compensation payable for any one incident will be limited to a combined total of 750 million Special Drawing Rights (SDR) including the amount of compensation paid under the existing CLC/Fund Convention. Annual contributions to the Fund will be made in respect of each Contracting State by any person who, in any calendar year, has received total quantities of oil exceeding 150,000 tons. However, for the purposes of the Protocol, there is a minimum aggregate receipt of 1,000,000 tons of contributing oil in each Contracting State.

6.6 International Convention on Liability and Compensation for Damage in Connection with the Carriage of Hazardous and Noxious Substances by Sea (HNS), 1996 (and its 2010 Protocol): ${ }^{40}$

(Adoption: 3 May 1996; Not in force; superseded by 2010 Protocol: Adoption: 30 April 2010;Not yet in force)

The HNS Convention was adopted in 1996 to make it possible for up to 250 million SDR to be paid out in compensation to victims of accidents involving HNS, such as chemicals. The Convention is based on the twotier system established under the CLC and Fund Conventions. However, it goes further in that it covers not only pollution damage but also the risks of fire and explosion, including loss of life or personal injury as well as loss of or damage to property.

HNS are defined by reference to lists of substances included in various IMO Conventions and Codes. These include oils; other liquid substances defined as noxious or dangerous; liquefied gases; liquid substances with a flashpoint not exceeding $60^{\circ} \mathrm{C}$; dangerous, hazardous and harmful materials and substances carried in packaged form; and solid bulk materials defined as possessing chemical hazards. The Convention also covers residues left by the previous carriage of HNS, other than those carried in packaged form. The Convention defines damage as including loss of life or personal injury; loss of or damage to property outside the ship; loss or damage by contamination of the environment; the costs of preventative measures and further loss or damage caused by them.

The Convention introduces strict liability for the ship-owner and a system of compulsory insurance and insurance certificates.A lack of ratifications meant that the 1996 Convention was failing to come into force and as a result, a Protocol was developed to address practical problems that had prevented many States from ratifying the original Convention. The 2010 Protocol to the International Convention on Liability and Compensation for Damage in Connection with the Carriage of Hazardous and Noxious Substances by Sea, 1996 (HNS Convention), was adopted by consensus by a Diplomatic Conference convened by IMO in April 2010.

\subsubsection{Limits of Liability under the 2010 Protocol:}

Under the 2010 Protocol, if damage is caused by bulk HNS, compensation would first be sought from the ship-owner, up to a maximum limit of 100 million Special Drawing Rights (SDR). Where damage is caused by packaged HNS, or by both bulk HNS and packaged HNS, the maximum liability for the ship-owner is 115 million SDR. Once this limit is reached, compensation would be paid from the second tier, the HNS Fund, up to a maximum of 250 million SDR (including compensation paid under the first tier).

\subsection{HNS (Hazardous Noxious Substances) Fund: ${ }^{41}$}

It has generally been agreed that it would not be possible to provide sufficient cover by the ship-owner liability alone for the damage that could be caused in connection with the carriage of HNS cargo. This liability,

\footnotetext{
${ }^{39}$ Supra note 8 , at 245 .

${ }^{40}$ Supra note 19.

${ }^{41}$ www.marentas.com. (Accessed on 2-Sep-14).
} 
which creates a first tier of the Convention, is therefore supplemented by the second tier, the HNS Fund, financed by cargo interests. The Fund will become involved:because no liability for the damage arises for the ship-owner. This could occur, for example, if the ship-owner was not informed that a shipment contained HNS or if the accident resulted from an act of war;because the owner is financially incapable of meeting the obligations under this Convention in full and any financial security that may be provided does not cover or is insufficient to satisfy the claims for compensation for damage, orbecause the damage exceeds the owner's liability limits established in the Convention.Contributions to the second tier will be levied on persons in the Contracting Parties who receive a certain minimum quantity of HNS cargo during a calendar year. The tier will consist of one general account and three separate accounts for oil, liquefied natural gas (LNG) andliquefied petroleum gas (LPG). The system with separate accounts has been seen as a way to avoid cross-subsidization between different HNS substances. The HNS Convention excludes pollution damage as defined in the CLC andFund, to avoid an overlap with these Conventions. However, HNS covers other damage (including death or personal injury) as well as damage caused by fire and/or explosion when oils are carried.

\subsection{International Convention on Civil Liability for Bunker Oil Pollution Damage, 2001: ${ }^{42}$} (Adoption: 23 March 2001; Entry into force: 21 November 2008)

The Convention was adopted to ensure that adequate, prompt, and effective compensation is available to persons who suffer damage caused by spills of oil, when carried as fuel in ships' bunkers. The Convention applies to damage caused on the territory, including the territorial sea, and in exclusive economic zones of States Parties.

The bunkers convention provides a free-standing instrument covering pollution damage only. "Pollution damage" means:

(a) loss or damage caused outside the ship by contamination resulting from the escape or discharge of bunker oil from the ship, wherever such escape or discharge may occur, provided that compensation for impairment of the environment other than loss of profit from such impairment shall be limited to costs of reasonable measures of reinstatement actually undertaken or to be undertaken; and

(b) The costs of preventive measures and further loss or damage caused by preventive measures. The convention is modelled on the CLC and a key requirement in the bunkers convention is the need for the registered owner of a vessel to maintain compulsory insurance cover.

The convention is modelled on the International Convention on Civil Liability for Oil Pollution Damage, 1969. As with that convention, a key requirement in the bunkers convention is the need for the registered owner of a vessel to maintain compulsory insurance cover. Another key provision is the requirement for direct action this would allow a claim for compensation for pollution damage to be brought directly against an insurer. The Convention requires ships over 1,000 gross tonnage to maintain insurance or other financial security, such as the guarantee of a bank or similar financial institution, to cover the liability of the registered owner for pollution damage in an amount equal to the limits of liability under the applicable national or international limitation regime, but in all cases, not exceeding an amount calculated in accordance with the Convention on Limitation of Liability for Maritime Claims, 1976, as amended.The Convention will come into force one year after the ratification or accession by 18 states, five of which must have ships of combined gross tonnage of at least 1 million. ${ }^{43}$

\section{The Civil Liability Regime as a Legal Norm for Marine Oil Pollution:}

The civil liability regime as it applies under the 1992 Civil Liability and Fund Conventions 1973 to ship-sourced oil pollution has been recognized as being at the forefront of establishing a legal norm for marine pollution compensation, advancing private law remedies to enable victims of oil spillage to recover financial recompense on a strict liability basis from the liability insurers of ship owners. ${ }^{44}$ The method of compensation under this regime strict liability (without the need to prove negligence) up to a maximum limit backed by compulsory insurance has been widely acknowledged as an effective and equitable means of incorporating the 'polluter pays' principle into the field of marine environmental liability. ${ }^{45}$

Civil liability regimes such as the 1992 Civil Liability and Fund Conventions compulsorily oblige the responsible parties (i.e. the ship-owner in the context of the 1992 Civil Liability and Fund Conventions) to

\footnotetext{
${ }^{42}$ Christopher Hill, Maritime Law, 6th Ed. (Hong Kong, 2003), pp. 441.

${ }^{43} I d$.

${ }^{44}$ S. Philippe, Principles of International Environmental Law, (Cambridge University Press, UK, 2003).
}

${ }^{45} I d$. 
maintain insurance to cover its liability and enable victims to seek recourse directly against the insurer. As such, civil liability regimes enhance the utility of the management of risk since the larger risk of oil pollution damage compensation is removed from the insured by the payment of a relatively small premium and the transaction cost is reduced as it is already decided ex ante through the conditions of the insurer who should intervene and bear the costs when an incident occurs. However, the adoption of a strict liability rule for oil pollution damage is not without its critics. Adopting an economic analysis of the law, note that there is a direct linear relationship between the magnitude of the accident risk and the amount spent on care by the potential polluter and criticize the orthodox rationale favoring a limited strict liability rule for oil pollution damage that only a strict liability rule would lead to full internalization of the costs involved of these highly risky activities. ${ }^{46}$

\section{Compensation and Liability of States for Marine Oil Pollution:}

Liability of the responsible parties and the compensation principals and procedures related with the damages for the ships and coastal facilities under this law have been determined with the OSRL and its implementation regulation. Liable parties of ships and coastal facilities under the OSRL (Oil Spill Response Limited)are liable jointly and separately for:

$>$ Compensation of expenditures for cleaning;

$>$ Expenditures for preventive measures;

$>$ Any damage to living resources and marine life;

$>$ Reinstatement of degenerated environment;

$>$ Expenditures for transport and disposal of any waste collected;

$>$ Damages to natural or living resources that are exploited for subsistence purposes;

$>$ Damage to private property;

$>$ Losses stemming from personal injury or death;

$>$ Loss of income, damage to capacity to earn income or revenues; and

$>$ Other public losses caused by pollution or risk of pollution stemming from any incident involving vessels or coastal facilities in any area of enforcement.

Procedures for compensation of damages and notification of the guarantees of financial liabilities will be implemented by the UMA. Establishment and working procedures of the damage identification commission are prescribed by in the OSRL Implementation Regulation. Ships carrying oil and oil products requesting entry to areas of enforcement are obliged to possess documents of financial liability pursuant to international conventions signed by Turkey and coastal facilities are obliged to have financial insurance against the damages under the law. ${ }^{47}$

\section{Compliance with and Enforcement of International Environmental Law andChallenges: ${ }^{48}$}

Responding to the interdependence of ecosystems and defining the scope of the 'environment' protected are not the only challenges to confront international environmental law: other challenges cut across the various areas of international environmental regulation that are-

First, there are questions over the adequacy of the legislative process in international environmental law. These questions relate to substance (whether international law can be marshalled effectively to promote environmental protection) and questions of law-making procedure (whether multilateral processes based upon securing consensus amongst states are feasible). A related issue is the extent to which international environmental law continues to be underpinned by general principles for guidance on how to achieve central objectives, includingSustainable development.

Second, even where international environmental rules exist, there are difficulties of enforcement, particularly where environmental protection objectives come into conflicteconomic interests. The steady increase in international environmental jurisprudence over the past decade might indicate that prospects for enforcement are improving, but the reality is that few international courts or tribunals have shown themselves to be willing to give a hard edge to norms of environmental protection.

Third, many of the rules of international environmental law depend for their effectiveness ondomestic implementation. Ambitious environmental protection goals at the international levelwill not are meaningful

\footnotetext{
${ }^{46} I d$.

${ }^{47}$ http://www.imo.org. (n.d.), from http://www.imo.org/blast/mainframe.asp?topic id=23, (Accessed on 2-sep-14).

${ }^{48}$ Philippe Sands, Jacqueline Peel, Adriana Fabra, Ruth MacKenzie, Principles of International Environmental Law, ${ }^{\text {rd }}$ Edition, (Cambridge University Press. 2012).
} 
unless they are implemented at the national level, and this requiresgreater attention to be given to the reasons why international rules on environmental protection suffer from inadequate domestic implementation.

Fourth, although the importance of scientific knowledge to international environmental regulation is widely acknowledged, questions remain around how best to marshal scientific advice in the legislative, administrative and adjudicative processes of international environmental law.

Fifth, the growth of international environmental law in the last few decades, and its penetration into a variety of other international areas including trade and human rights, raises important challenges of integration and interlink age.

\section{Vessel Pollution: Compliance and Enforcement Challenges:}

The International Maritime Organization (IMO), an agency of the United Nations, is the central governing body that deals with issues of vessel pollution. Several key conventions established by the IMO constitute the core legal framework governing vessel pollutants. These include: International Convention for the Prevention of Pollution from Ships (MARPOL), 1973/78, the International Convention for the Control and Management of Ships' Ballast Water and Sediments, 2004, the International Convention on Oil Pollution Preparedness, Response and Co-operation (OPRC), 1990, and the International Convention for Safety at Sea (SOLAS), 1974. ${ }^{49}$ Other international, regional and national agreements exist to address vessel pollution as well. The most common violations are the result of discharge of waste through bypass equipment, false records, repeated tampering with monitoring system, discharge of bilge waste and sludge through bypass equipment, and obstruction of investigations. ${ }^{50}$ The most common violations are the result of discharge of waste through bypass equipment, false records, repeated tampering with monitoring system, discharge of bilge waste and sludge through by pass equipment, and obstruction of investigations. ${ }^{51}$ The estimated operational oil discharge from compliant tankers is 34 tons per year, and the estimated operational oil discharge from non-compliant tankers is 1,129 tons per year. ${ }^{52}$ Worldwide it is estimated that 85 percent of commercial vessels and 70percent of other vessels are compliant with MARPOL regulations on bilge oil discharge. ${ }^{53}$ Compliance rates for fuel oil sludge discharge regulation is assumed to be at 95 percent for tankers with 18,400 tons of discharge per year, and 85 percent for non-tankers with sludge discharge of 237,299 tons per year. ${ }^{54}$

Technical tools can aid in enforcement and achieve compliance. For example, tamper-resistant recording systems, alarms, and printouts to verify equipment operation, valve position, flow, incineration, and ship's position can ease the challenges of vessel pollution enforcement. ${ }^{55}$ Vessel Monitoring Systems (VMS), remote sensing, database systems, and technical assistance programs help to achieve compliance and enforcement in fisheries, as well as with respect to illegal discharges and dumping. However, in many cases, technological disparities (including the lack of internet access) hinder the dissemination of information to countries and fishing communities, preventing optimal implementation of policies. While new technologies can be expensive, over time these costs may drop and provide more inexpensive means to conduct monitoring, surveillance, and enforcement operations. However, many developing countries are likely to require technical, financial, and personnel assistance in deploying and utilizing these technologies to improve compliance and enforcement.

\section{Land-Based Marine Pollution: Compliance and Enforcement Challenges:}

International and multilateral agreements that attempt to address land based sources of marine pollution and include the following:

- United Nations Convention on the Law of the Sea, Articles 207 and 213;

$>$ Agenda 21 of the United Nations Conference on Environment and Development;

$>$ The Global Programme of Action for the Protection of the Marine-Environment from Land-Based Activities (GAP); and

\footnotetext{
${ }^{49}$ Prevention of Marine Pollution Conventions.(2013), from www.imo.org.(Accessed on 3-Sep-14).

${ }^{50}$ Intertanko, Criminal Vessel Enforcement. Fromwww.intertanko.com/upload/presentations.(Accessed on 3-Sep-14).

${ }^{51} I d$.

52 Committee on Oil in the Sea: Inputs, Fates, and Effects, National Research Council. Oil in the Sea III:Inputs, Effects and Fates, 2003.http://books.nap.edu/openbook.php?record id=10388\&page=208.(Accessed on 3-Sep-14).

${ }^{53}$ Committee on Oil in the Sea: Inputs, Fates, and Effects, National Research Council. Oil in the SeaIII: Inputs, Effects and Fates, 2003. http://books.nap.edu/openbook.php?record_id=10388\&page=210.(Accessed on 3-Sep-14).

${ }^{54}$ Committee on Oil in the Sea: Inputs, Fates, and Effects, National Research Council. Oil in the SeaIII: Inputs, Effects and Fates, 2003. http://books.nap.edu/openbook.php?record_id=10388\&page=210.(Accessed on 3-Sep-14).

${ }^{55}$ The Shipping Industry's Guide to Oil Water Separators, (2006).(Accessed on 4-Sep-14).
} 
$>$ UN Millennium Goals.

Complicating the ability to address Tran's boundary land-based marine pollution is the difficulty of identifying pollution from nonpoint and atmospheric sources. Inability to easily identify violations prevents governments from determining responsibility, extracting payments, and enforcing compliance. Furthermore, the need for compliance may be masked by the lack of mechanisms to value the full set of ecosystem services affected rather than just the more easily measured cash values generated by destructive activities. Also, environmental impacts may seem small and inconsequential for individual actors but cause major changes to ecosystems in the aggregate. ${ }^{56}$ Fragmented management systems and the number of distinct stakeholders and sectors responsible for polluting further complicates attempts at addressing compliance and enforcement of land based marine pollution. Additionally, financial constraints, such as cost of appropriate infrastructure facilities and equipment, and the potential implications for local livelihoods, serve as obstacles to compliance and enforcement. This is especially true in Small Island Developing States (SIDS), where marine degradation can be acutely felt, and resources for addressing land-based pollution are limited. ${ }^{57}$

\section{Conclusion:}

Protection and preservation of marine environment has become one the most important ecological issues of modern time. ${ }^{58}$ The sources of human induced source of marine pollution are numerous. Among the sources, one is ship source pollution. There is a need for the protection of man from activities that may cause damage to his property, his physical existence or his legitimate activities. In this regard, marine pollution has to be controlled because it causes damage. From an ecological perspective, ocean is an essential component to sustain lives on earth. The protection of ocean was largely neglected although there is a general emergence of environmental consciousness in the past few decades. Prevention of oil pollution of the marine environment by ocean vessels pollution as one of the major threats to the ocean is adequately regulated by a legal framework created by international law. While the international community has made significant strides in developing agreements, rules, and regulations to improve ocean and coastal management, compliance and enforcement of these instruments often lags. This is true at the international, national, and sub-national levels. This is due variously to insufficient institutional mechanisms and mandates, capacity, and political will. Improving compliance and enforcement of ocean and coastal management will require a range of initiatives, including a suite of regulatory and non-regulatory mechanisms (such as incentives, planning, and information-based approaches) to develop and enhance compliance mechanisms and approaches at the international level, as well as to enhance national and sub-national capacity to implement and enforce.

While the international community has made significant strides in developingagreements, rules, and regulations to improve ocean and coastal management, compliance and enforcement of these instruments often lags. This is true at theinternational, national, and sub-national levels. This is due variously to insufficientinstitutional mechanisms and mandates, capacity, and political will. Improvingcompliance and enforcement of ocean and coastal management will require a range ofinitiatives, including a suite of regulatory and non-regulatory mechanisms (such asincentives, planning, and information-based approaches) to develop and enhancecompliance mechanisms and approaches at the international level, as well as to enhance national and sub national capacity to implement and enforce. At the international level, the costly operational and structural requirements prescribed in the regulatory conventions still pose a great burden on developing countries with large tonnages and those major ship registries as well as second-hand ships receivers. Therefore more effort is needed by the international maritime community to promote international co-operation between well developed and less developed countries, especially in technical and financial support for the less developed states, so as to achieve international success in the prevention and control of vessel source pollution. In addition to the lack of proper laws for the prevention of pollution by vessels, currently there are multiple authorities dealing with one or more aspects of pollution prevention in the country, which makes the system more complex. Therefore there is a need to establish a centralized authority whose responsibilities are clearly defined. In this vein, there is also a need to strengthen the institutional framework for preventive monitoring andenforcement. Moreover, collaboration with other States is important to overcome theInternational problem of marine pollution.

\footnotetext{
${ }^{56} \mathrm{http}: / /$ www.gpa.unep.org/documents/2006_npa_handbook_for_english.pdf, at p. 16.(Accessed on 3-Sep-14).

${ }^{57}$ Arwen $\mathrm{L}$ Edsall, Integrating Watershed and Coastal Resource Management: Wider Caribbean (2007)http://www.csc.noaa.gov/cz/2007/Coastal_Zone_07_Proceedings/PDFs/Poster_Abstracts/3452.Edsall.pdf.

${ }^{58}$ Khee, J., T. A. Jin, Vessel-Source Marine Pollution. Cambridge, (Cambridge University Press, UK, 2006). 


\section{International Instruments:}

\section{References:}

[1]. International Convention for the Prevention of Pollution from Ships (MARPOL)

[2]. International Convention on Civil Liability for Oil Pollution Damage (CLC)

[3]. International Convention on Oil Pollution Preparedness, Response and Co-operation (OPRC)

[4]. International Convention on the Establishment of an International Fund for Compensation for Oil Pollution Damage (FUND)

[5]. The 2003 Protocol (Supplementary Fund)

[6]. HNS (Hazardous Noxious Substances) Fund

[7]. International Convention on Civil Liability for Bunker Oil Pollution Damage, 2001

\section{Journal Papers:}

[8]. M. Gennaro, Oil Pollution Liability and Control under International Maritime Law, Vanderbilt Journal of Transnational Law, 37:265(01), 2004, $265-298$

[9]. YAN XIAOLU,The International Legal Framework for Prevention of Vessel-source Pollution and Its Implementation in Chinese Legislation.(Faculty of Law, Lund University, 2011).

[10]. D. Brubaker, Environmental Protection of Arctic Waters Specific Focus the Northern Sea Route, (Stockholm, 2002).

\section{Books:}

[11]. Dr. N. V. Vinithkumar, Marine Pollution a Perspective, Monitoring and Control in India, (1st edn.) (Marine Institute of India.2012).

[12]. Jin-Tan, Alan Khee, Vessel-Source Marine Pollution, (Cambridge University Press; Cambridge, 2006).

[13]. Edgar Gold, Handbook on Marine Pollution, (University of Virginia, Arendal, Assuranceforeningen Gard, 1985).

[14]. D. Brubaker, Marine Pollution and International Law; Principles and Practice, (Belhaven Press, London and Florida, 1993)

[15]. DavorVidas, (eds.), Law, Technology and Science for Oceans in Globalization; IUU Fishing, Oil Pollution, Bio prospecting, (Outer Continental Shelf, Leiden, Boston, 2010).

[16]. E. Gold, A.Chircop, and H. Kindred, Maritime Law, (Irwin Law Irwin Law, Canada, 2004)

[17]. D. Brubaker, Environmental Protection of Arctic Waters Specific Focus the Northern Sea Route,(Stockholm, 2002).

[18]. Al, R. C., The Law of the Sea, ( $2^{\text {nd }}$ edition ed.), (Manchester, UK: Manchester University Press, 1988).

[19]. R. A Duce, P. L. Parker \& C. S. Giam., Pollutant transfer to the marine environment, Deliberations and recommendations of the NSF/ IDOE pollutant transfer workshop held in Port, (Texas, USA: Kingston, Rhode Island, 1974).

[20]. A. B. Patricia Birnie, International Law and the Environment.(OUP 2009)

[21]. Christopher Hill, Maritime Law, 6th Ed. (Hong Kong, 2003).

[22]. S. Philippe, Principles of International Environmental Law, (Cambridge University Press, UK, 2003).

[23]. Philippe Sands, Jacqueline Peel, Adriana Fabra, Ruth MacKenzie,Principles of International Environmental Law,3rd Edition, (Cambridge University Press. 2012).

[24]. Khee, J., T. A. Jin, Vessel-Source Marine Pollution. Cambridge, (Cambridge University Press, UK, 2006).

\section{Internet:}

http://www.imo.org/includes/blast Data Only/data_id.

http://www.niot.res.in/m5/mbic/me/data/me.pdf.

http://wwf.panda.org/about_our_earth/blue_planet/problems.

http://www.marentas.com.

http://www.intertanko.com/upload/presentations

http://books.nap.edu/openbook.php?record_id.

http://www.gpa.unep.org/documents/2006 npa handbook for english.pdf.

http://www.csc.noaa.gov/cz/2007/Coastal_Zone_07_Proceedings/PDFs/Poster_Abstracts/3452.Edsall.pdf. 